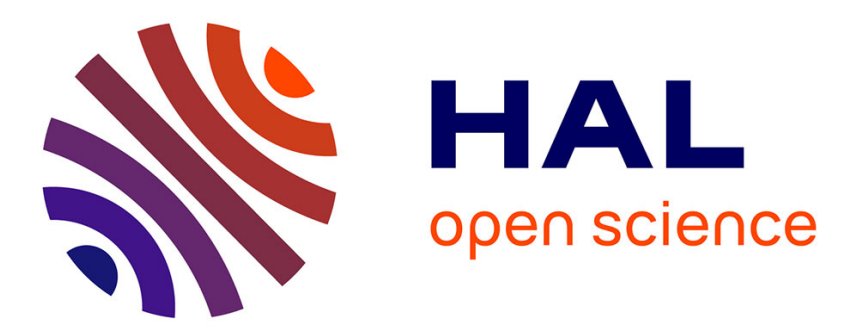

\title{
Palladium pincer complexes featuring an unsymmetrical SCN indene-based ligand with an hemilabile pyridine sidearm
}

\author{
Paul Brunel, Chloé Lhardy, Sonia Mallet-Ladeira, Julien Monot, Blanca \\ Martin-Vaca, Didier Bourissou
}

\section{To cite this version:}

Paul Brunel, Chloé Lhardy, Sonia Mallet-Ladeira, Julien Monot, Blanca Martin-Vaca, et al.. Palladium pincer complexes featuring an unsymmetrical SCN indene-based ligand with an hemilabile pyridine sidearm. Dalton Transactions, 2019, 48 (26), pp.9801-9806. 10.1039/C9DT00898E . hal02398806

\section{HAL Id: hal-02398806 https://hal.science/hal-02398806}

Submitted on 8 Dec 2019

HAL is a multi-disciplinary open access archive for the deposit and dissemination of scientific research documents, whether they are published or not. The documents may come from teaching and research institutions in France or abroad, or from public or private research centers.
L'archive ouverte pluridisciplinaire HAL, est destinée au dépôt et à la diffusion de documents scientifiques de niveau recherche, publiés ou non, émanant des établissements d'enseignement et de recherche français ou étrangers, des laboratoires publics ou privés. 
Palladium pincer complexes featuring an unsymmetrical SCN indene-based ligand with an hemilabile pyridine sidearm

Paul Brunel, ${ }^{a}$ Chloé Lhardy, ${ }^{a}$ Sonia Mallet-Ladeira, ${ }^{b}$ Julien Monot, ${ }^{* a}$ Blanca Martin-Vaca*a and Didier Bourissou*a

a. CNRS, Université Paul Sabatier, Laboratoire Hétérochimie Fondamentale et Appliquée (LHFA, UMR 5069), 118 Route de Narbonne, 31062 Toulouse Cedex

09, France.Email: monot@chimie.ups-tlse.fr; bmv@chimie.ups-tlse.fr and dbouriss@chimie.ups-tlse.fr

b. Université de Toulouse, UPS, Institut de Chimie de Toulouse, FR2599, 118 Route de Narbonne, F-31062 Toulouse, France.

Abstract: The new unsymmetrical indene-based pro-ligand featuring thiophosphinoyle and methylpyridine sidearms 2 was prepared. Coordination and cyclometalation in the presence of [ $\mathrm{PdCl} 2(\mathrm{PhCN}) 2]$ and PS-DIEA afforded three well-defined 2-indenyl SCN pincer complexes 3a-c. The lability of the pyridine moiety has been evidenced upon treatment with triphenylphosphine and 2,6-dimethylphenylisocyanide. In addition, reversible CPd bond cleavage has been demonstrated under Brönsted acid/base conditions. The indenediide SCN pincer complex 4 was prepared by deprotonation of $3 a$ in the presence of triphenylphosphine. Preliminary catalytic tests on the cyloisomerization of 4-pentynoic acid have underlined the impact of the pyridine sidearm on catalytic activity.

\section{Introduction}

Over the last decades, metal/ligand cooperativity (MLC) has become a very active and flourishing domain in catalysis, in particular thanks to the progress of the chemistry of pincer complexes. ${ }^{1}$ Starting from ruthenium pincer complexes, MLC has been developed with different late transitions metals ( $\mathrm{Ru}, \mathrm{Rh}, \mathrm{Ir} \ldots),{ }^{2}$ and more recently first row transition metals (Fe, Mn, Ni...). ${ }^{3} \mathrm{Despite}$ the forefront position of Pd in catalysis, scarce examples of MLC involve Pd pincer complexes so far..$^{4,5}$ This is most likely due to the tridentate nature of pincer ligands and to the square-planar geometry of Pd(II) which result in only one available "working" site at $\mathrm{Pd}$, limiting thereby the variety of possible transformations.

To overcome this limitation, the design of a hemilabile pincer ligand is appealing. According to the HSAB theory, ${ }^{6}$ the soft Pd(II) prefers soft donor atoms such as $\mathrm{P}$ or $\mathrm{S}$ over hard $\mathrm{N}$ donors. Accordingly, the incorporation of a $\mathrm{N}\left(\mathrm{sp}^{2}\right)$ lateral donor site into a tridentate ligand is attractive to achieve hemilability in pincer Pd(II) complexes. Wendt and coll. ${ }^{7}$ applied this strategy for the preparation of a hemilabile unsymmetrical PCN palladium pincer complex and demonstrated its efficiency in the catalytic decarboxylative cross-coupling of propiolic acids and aryl halides.

As part of our ongoing research program on indenediide pincer complexes (Chart 1, compound A), ${ }^{4 b, c}$ we have demonstrated the high structural modularity of these systems and improved thereby their catalytic activity in cycloisomerization reactions. Seeking for further structural modifications, we reported last year the synthesis of a tridentate indene-based ligand with two pyridine sidearms. Coordination to Pd afforded the pincer complex $\mathbf{B}$ (Chart 1) with migration of the CC double bond. ${ }^{8}$

Here, we report the preparation of a new unsymmetrical indene-based ligand featuring thiophosphinoyle and methylpyridine sidearms as a fusion of models $\mathbf{A}$ and $\mathbf{B}$ (Chart 1, compounds $\mathbf{C}$ ). Coordination to Pd leading to the corresponding indenyl and indenediide pincer complexes is described. The hemilability of the pyridine moiety and its impact on the catalytic activity of the indenediide pincer complex are discussed.

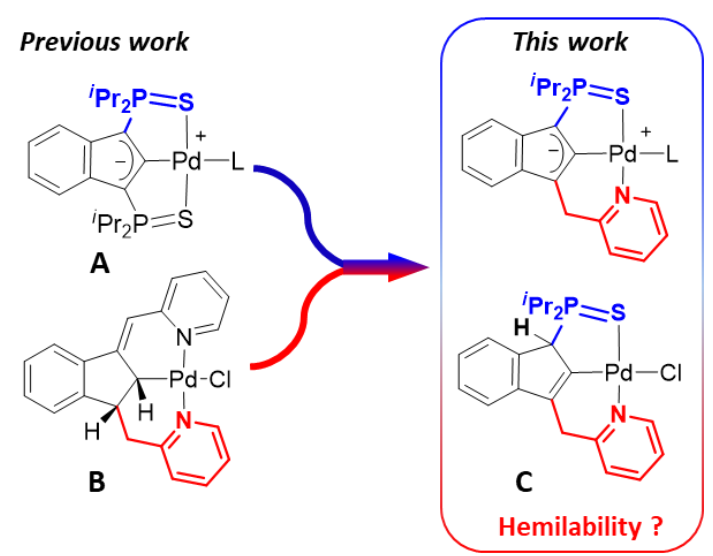

Chart 1. Bisthiophosphinoyl-indenediide (A), bismethylpyridine-indenyle (B) and the new thiophosphinoyl-methylpyridine indenyl and indenediide (C) Pd pincer complexes. 


\section{Results and discussion}

\section{Preparation of the indenyl and indenediide complexes (3a-c, 4)}

Starting from compound $\mathbf{1},{ }^{8}$ the pro-ligand $\mathbf{2}$ was readily prepared by deprotonation and addition of chlorodiisopropylphosphine followed by oxidation with an excess of elemental sulphur (scheme 1). After purification by flash chromatography, compound $\mathbf{2}$ was obtained in $76 \%$ yield as a brown viscous oil. The introduction of the thiophosphinoyle arm is confirmed by the appearance of a sharp singlet at $70 \mathrm{ppm}$ in ${ }^{31} \mathrm{P}$ NMR spectroscopy. The ${ }^{1} \mathrm{H}$ NMR signal for the $\mathrm{C}_{\mathrm{sp} 3}-\mathrm{H}$ bearing the thiophosphinoyle sidearm appears with the expected multiplicity (dd, $J_{H P}=23.5$ and $J_{H H}=1.8 \mathrm{~Hz}$ ) at $4.26 \mathrm{ppm}$, similarly to what was observed for the bis(thiophosphinoyle) indene pro-ligand (Chart $1, \mathbf{A}) .^{4 \mathrm{~b}}$

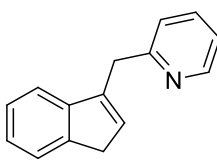

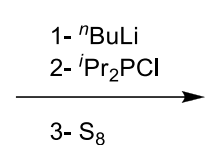

3- $S_{8}$

Scheme 1. Preparation of the pro-ligand 2 from 1.

Then, pro-ligand 2 was reacted with $\left[\mathrm{PdCl}_{2}(\mathrm{PhCN})_{2}\right]$ in $\mathrm{DCM}$ at room temperature. After 30 min, an important precipitate was observed. The absence of ${ }^{31} \mathrm{P}$ NMR signal indicated complete consumption of $\mathbf{2}$. The high insolubility of the solid obtained after filtration prevented its characterization. Surmising that this precipitate results from the protonation of the pyridine sidearm upon activation of the $\mathrm{C} 1-\mathrm{H}$ bond, the reaction of 2 with $\left[\mathrm{PdCl}_{2}(\mathrm{PhCN})_{2}\right]$ was performed in the presence of polystyrene-supported diisopropylethyl amine (PS-DIEA) as an external base. After $30 \mathrm{~min}$ in DCM at room temperature, ${ }^{31} \mathrm{P}$ NMR spectroscopy showed complete consumption of $\mathbf{2}$ and the apparition of two well-defined species giving rise to singlet signals at 81.9 and 82.5 ppm (in a 7 / 3 ratio, Scheme 2). Increasing the reaction time to $20 \mathrm{~h}$ in order to probe the interconversion between them, lead in fact to the formation of a third compound as apparent from the additional singlet observed at $84.9 \mathrm{ppm}$ in the ${ }^{31} \mathrm{P}$ NMR spectrum. These three species could be separated by flash chromatography with a good overall yield (76\%). Stopping the reaction at 30 min allows to obtain $3 \mathbf{a}$ as the major product.

For the three complexes, the coordination of both the thiophosphinoyle and pyridine sidearms to the Pd center was confirmed by NMR spectroscopy in $\mathrm{CDCl}_{3}$. For each species, the ${ }^{31} \mathrm{P}$ NMR spectra displays a sharp singlet (at 81.9 and 82.5 ppm, respectively) shifted downfield by at least $10 \mathrm{ppm}$ compared to that of the pro-ligand (70 ppm). In the ${ }^{1} \mathrm{H}$ NMR spectrum, the $\mathrm{H}_{\text {ortho }}$ of the pyridine ring is shifted downfield for all complexes $\mathbf{3}(9.61,9.70$ and $9.93 \mathrm{ppm})$ with respect to that of $\mathbf{2}(8.55 \mathrm{ppm})$.

In the case of compound $\mathbf{3 b}$, the carbon atom connecting the pyridine to the ligand backbone is no longer part of a $\mathrm{CH}_{2}$ group but a $\mathrm{C}_{\mathrm{sp} 2}-\mathrm{H}$ group, as indicated by the ${ }^{1} \mathrm{H}$ and ${ }^{13} \mathrm{C}$ NMR signals at 6.94 and $115.5 \mathrm{ppm}$, respectively. This indicates migration of the $\mathrm{C}=\mathrm{C}$ double bond, as in the case of the bis(pyridine)indenyl pincer complex B. ${ }^{8}$ Consistently, $\mathrm{C} 1$ and $\mathrm{C} 2$ display typical features for $\mathrm{C}_{\mathrm{sp} 3}-\mathrm{H}$ moieties $\left({ }^{13} \mathrm{C}\right.$ NMR: 53.6 and $37.1 \mathrm{ppm},{ }^{1} \mathrm{H}$ NMR: doublet of doublets at 4.63 and $5.12 \mathrm{ppm}$ ).

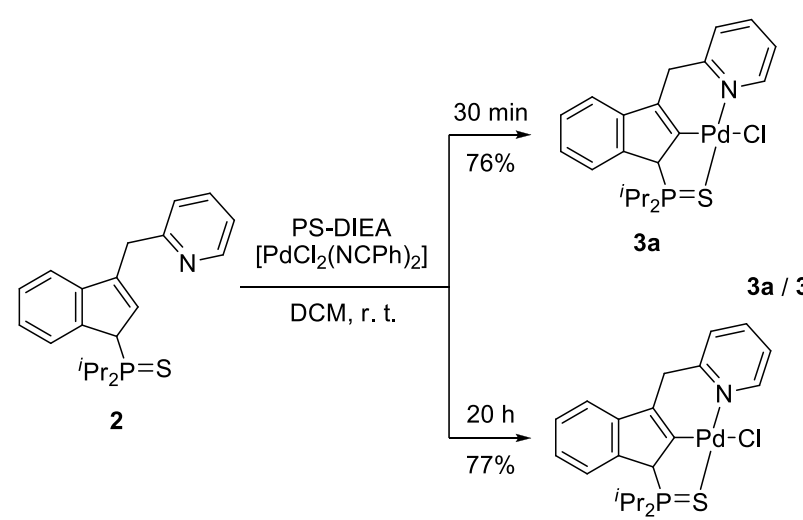

$3 a$<smiles>FC(F)(F)C1NP(=S)(Cl)C(=P)c2ccccc21</smiles>

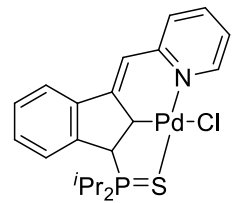

$3 b$

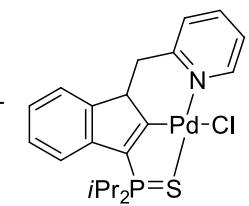

$3 c$

$3 a / 3 b / 3 c=4 / 3 / 3$

Scheme 2. Synthesis of the SCN Pd indenyle complexes 3. 


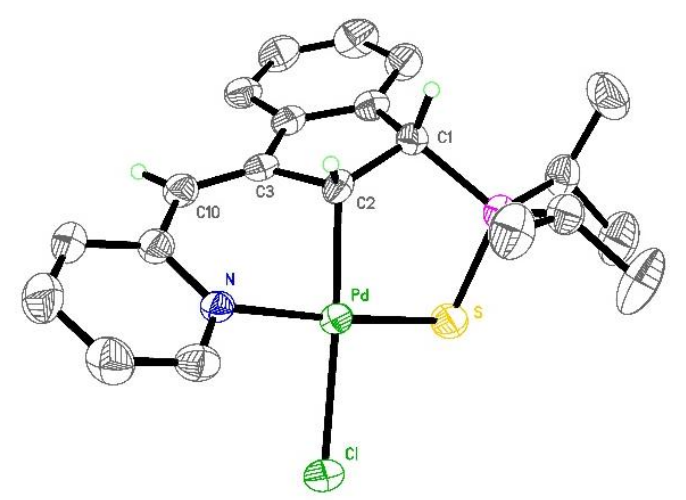

Figure 1. Ellipsoid drawings (50\% probability) of the molecular structure of $\mathbf{3 b}$. For clarity, lattice solvent molecules and hydrogen atoms are omitted, except $\mathrm{H} 1$, $\mathrm{H} 2$ and $\mathrm{H} 10$.

Crystals were grown by slow diffusion of pentane in a saturated dichloromethane solution at room temperature. The structure of $\mathbf{3 b}$ was definitely confirmed by X-ray diffraction analysis. As shown in Figure 1, the ligand is coordinated by $\mathrm{N}, \mathrm{C} 2$ and $\mathrm{S}$, and the Pd center in a slightly distorted square-planar environment. The C3 and C10 atoms are both in trigonal planar environment and form a CC double bond $\left(\mathrm{d}_{\mathrm{C} 3-\mathrm{C} 10}=1.345(6) \AA\right)$. Conversely, $\mathrm{C} 1$ and $\mathrm{C} 2$ are tetrahedral and the two respective $\mathrm{H}$ atoms ( $\mathrm{H} 1$ and $\mathrm{H} 2)$ are syn to each other. ${ }^{8}$

Assignment of complexes $\mathbf{3 a}$ and $\mathbf{3 c}$ as 2-indenyl Pd complexes, without migration of the CC double bond, was based on NMR spectroscopy. The ${ }^{13} \mathrm{C}$ NMR spectra clearly shows the presence of an aliphatic $\mathrm{CH}_{2}$ signal (at 37.48 and $39.45 \mathrm{ppm}$, respectively) for the methylpyridine sidearm. For $3 \mathbf{c}$, the $\mathrm{CH}_{2}$ protons resonate in ${ }^{1} \mathrm{H} \mathrm{NMR}$ as an $\mathrm{AM}$ system $(2.74$ and $3.46 \mathrm{ppm})$ due to the proximity of the asymmetric $\mathrm{C} 3$ center. The carbon of the indene directly bonded to $\mathrm{P}(\mathrm{C} 1)$ is quaternary and appears in the $\mathrm{C}_{\mathrm{sp} 2}$ zone $\left(135.5 \mathrm{ppm}, J_{\mathrm{CP}}=92.0 \mathrm{~Hz}\right)$. For $\mathbf{3 a}$, the $\mathrm{CH}$ signal at $63.77 \mathrm{ppm}$ displays a large coupling to phosphorus $\left(J_{C P}=45.8 \mathrm{~Hz}\right)$, as the associated ${ }^{1} \mathrm{H}$ NMR signal at $4.78 \mathrm{ppm}$ $\left(J_{H P}=20.6 \mathrm{~Hz}\right)$.

Having the palladium indenyl complexes $\mathbf{3}$ in hands, the preparation of the corresponding indenediide complex was attempted. First, a similar strategy to that applied for the synthesis of the bis(thiophosphinoyle) indenediide palladium dimer ${ }^{4 \mathrm{~b}}$ was tested on 3a, using NaHMDS as a base (Scheme 3, top). No deprotonation occurred but isomerization of $\mathbf{3 a}$ into $\mathbf{3} \mathbf{b}$ and $\mathbf{3} \mathbf{c}$ was observed.

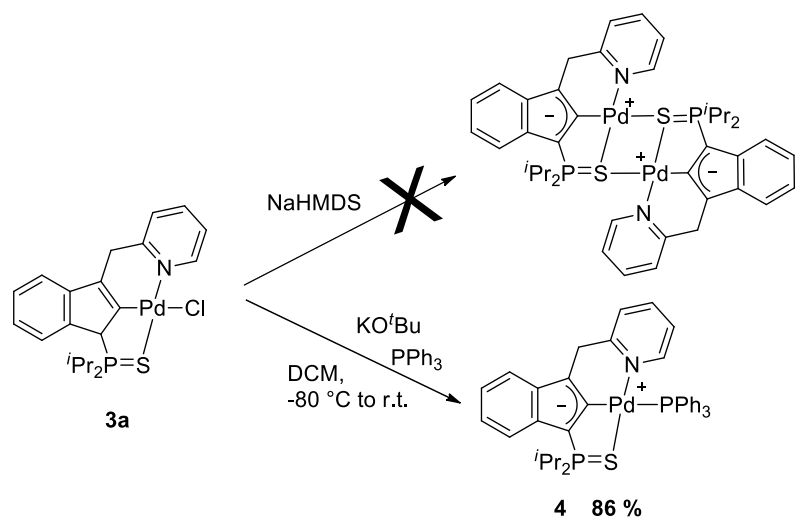

Scheme 3. Preparation of Pd indenediide complex 4.

At this stage, we decided to target a chloropalladate type complex using the previously reported procedure. ${ }^{4 \mathrm{~b}}$ Unfortunately, the addition of a base to $\mathbf{3 a}$ in the presence of ammonium chloride salt did not lead to the desired compound. Using ${ }^{t} \mathrm{BuOK}$ as the base in the presence of a more strongly coordinating co-ligand such as triphenylphosphine proved more fruitful, leading to a unique well-defined compound (Scheme 3, down). Complex 4 was isolated as a dark red powder after precipitation with pentane in an excellent yield (86\%). Two sharp doublet signals are observed in the ${ }^{31} \mathrm{P}$ NMR spectrum at 76.6 and $17.8 \mathrm{ppm}\left(J_{C P}=45.5 \mathrm{~Hz}\right)$ for the thiophosphinoyle sidearm and coordinated triphenylphosphine, respectively. Moreover, the disappearance of the $\mathrm{H}$ atom at $\mathrm{C} 1$ is clearly apparent from ${ }^{1} \mathrm{H}$ and ${ }^{13} \mathrm{C}$ NMR (a Cq signal is observed for $\mathrm{C} 1$ ), confirming the formation of an indenediide moiety. Complex 
4 is only moderately stable in solution. Its half-life time was estimated to $\sim 10 \mathrm{~h}$ in $\mathrm{CDCl}_{3}$ and $21 \mathrm{~h}$ in $d^{6}$-benzene at room temperature. ${ }^{9}$ This poor stability prevented the obtention of crystals suitable for X-ray diffraction analysis.

Evaluation of the hemilabity of the pyridine moiety.

The lability of the pyridine moiety of the pincer ligand was investigated next. Due to the low stability of $\mathbf{4}$ in solution, the study was carried out on the indenyl complexes 3 . The addition of increasing amounts of triphenylphosphine to a solution of $\mathbf{3 a}$ in $d^{2}$-DCM at room temperature was monitored by NMR spectroscopy (See Figure 2).

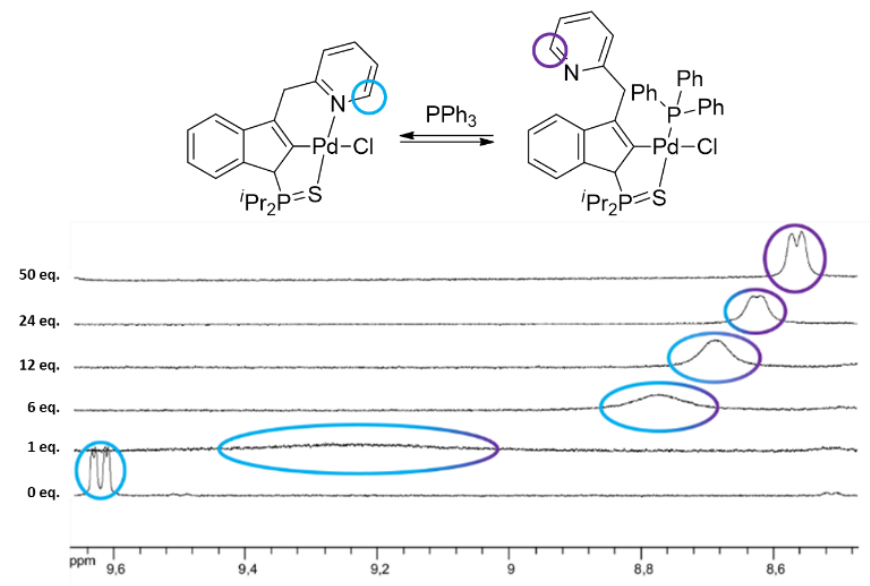

Figure 2. Stacking of ${ }^{1} \mathrm{H}$ NMR spectra for 3 a (region 9.70-8.50 ppm) with sequential additions of triphenylphosphine in $d^{2}$-DCM at $293 \mathrm{~K}$

The addition of triphenylphosphine resulted in a broadening and upfield shift of the ${ }^{1} \mathrm{H}$ NMR signal attributed to the $\mathrm{H}_{\text {ortho }}$ atom of the pyridine group (Figure 2). The ${ }^{31} \mathrm{P}$ NMR signal related to the thiophosphinoyle sidearm disappeared, whereas a new broad signal at $80.9 \mathrm{ppm}$ was observed. At the same time, the singlet signal corresponding to the free triphenylphosphine at $-5.18 \mathrm{ppm}$ significantly broadened and a second large signal appeared at $28.7 \mathrm{ppm}$. This is consistent with the coordination of $\mathrm{PPh}_{3}$ to $\mathrm{Pd}$ with relatively fast exchange between free and coordinated phosphine. Adding 50 equivalents of $\mathrm{PPh}_{3}$ resulted in a resolved doublet signal for $\mathrm{H}_{\text {ortho }}$ at $8.50 \mathrm{ppm}$ in the region of the free ligand (8.55 ppm for pro-ligand 2). All these observations are consistent with the displacement of the pyridine sidearm at $\mathrm{Pd}$ by $\mathrm{PPh}_{3}$ in the presence of an excess of the phosphine. However, the isolation and characterization of the resulting complex was unsuccessful due to the high fluxionality of the system.

In order to further substantiate the decoordination of the $\mathrm{N}$ sidearm, we turned to a less hindered partner, namely 2,6-dimethylphenyl isocyanide (Scheme 4). We hypothesized an easier displacement of the pyridine and thus, the use of a lower amount of the external co-ligand.

The addition of one equivalent of 2,6-dimethylphenyl isocyanide to a solution of $\mathbf{3 a}$ in $\mathrm{DCM}$ at $-80^{\circ} \mathrm{C}$ led to half conversion into a new compound 5 displaying a singlet at $71.8 \mathrm{ppm}$ in ${ }^{31} \mathrm{P}$ NMR. Two equivalents of isocyanide were necessary to convert quantitatively $\mathbf{3 a}$ into $\mathbf{5}$. The structure of $\mathbf{5}$ was determined by X-ray diffraction (crystals grown by slow diffusion of pentane in a saturated DCM solution at room temperature). A first observation confirms the decoordination of the pyridine sidearm and the coordination of an isocy anide to the Pd center. More surprising is the presence of a second unit of isocyanide inserted into the $\mathrm{Pd}-\mathrm{C}_{\mathrm{sp} 2}$ bond resulting in a 6-membered metallacycle with chair conformation. The palladium center is in a slightly distorted square-planar environment. The formation of $\mathbf{5}$ most likely results from displacement of the pyridine by an isocyanide, followed by its insertion into the $\mathrm{Pd}-\mathrm{C} 2$ bond and coordination of a second isocyanide unit. This is the first time that an insertion process into the central $\mathrm{Pd}-\mathrm{C}$ bond is observed with this kind of indenyle pincer complexes, but a similar process was previously reported by Gebbink and Szabó with $\mathrm{SC}_{\mathrm{sp} 2} \mathrm{~S}$ and $\mathrm{PC}_{\mathrm{sp} 2} \mathrm{~S}$ Pd pincer complexes. ${ }^{10}$

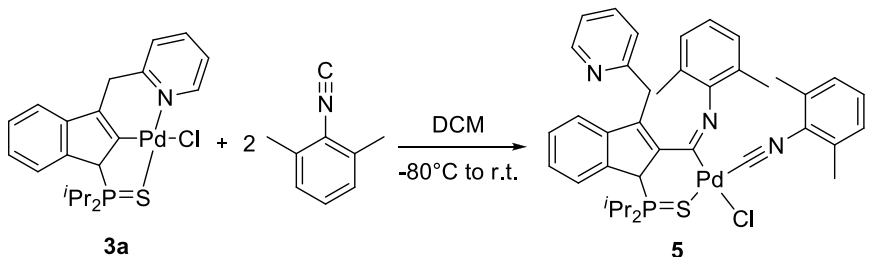

Scheme 4. Decoordination of the methylpyridine arm and insertion of an isocyanide unit. 


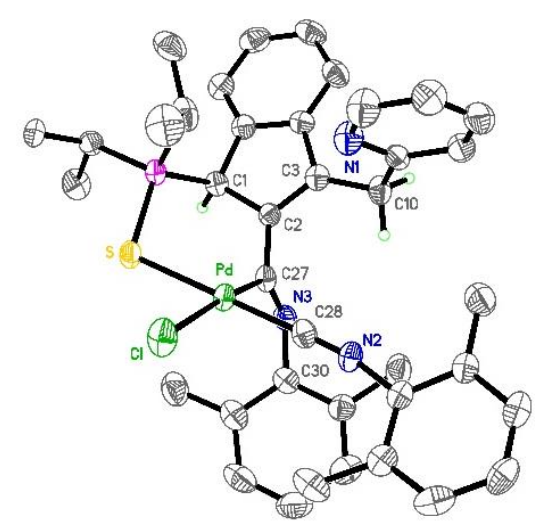

Figure 3. Ellipsoid drawings ( $50 \%$ probability) of the molecular structure of $\mathbf{5}$. For clarity, lattice solvent molecules and hydrogen atoms are omitted, except $\mathrm{H} 1$ and $\mathrm{H} 10$.

Thus, reacting the indenyl complex with a phosphine and an isocyanide established the lability of the pyridine. We then studied its behaviour under Brönsted acid/base conditions. While no reaction was observed upon addition of an excess of acetic acid (> 10 equivalents) to a solution of complex $\mathbf{3 b}$ in $d^{2}$-DCM, a clean and complete reaction was observed upon addition of three equivalents of trifluoroacetic acid. Close inspection of the ${ }^{1} \mathrm{H}$ and ${ }^{13} \mathrm{C}$ NMR data revealed the migration of the $\mathrm{C}=\mathrm{C}$ double bond to reform an indene moiety and the cleavage of the $\mathrm{C} 2-\mathrm{Pd}$ bond (Scheme 5). The ${ }^{1} \mathrm{H}$ NMR signal at $6.94 \mathrm{ppm}$ associated with the $-\mathrm{CH}=$ linker of $\mathbf{3 b}$ disappeared to give an $\mathrm{AM}$ system integrating for 2 protons (5.1 and $3.83 \mathrm{ppm}$ ) and correlating in ${ }^{13} \mathrm{C}$ NMR with an aliphatic $\mathrm{CH}_{2}$ signal (40.19 ppm). Concomitantly, the ${ }^{1} \mathrm{H}$ and ${ }^{13} \mathrm{C}$ NMR signals for the central $\mathrm{C}-\mathrm{H}$ moiety are noticeably deshielded as the result of the change in $\mathrm{C}$ hybridization (from $\mathrm{sp}^{3}$ to $\mathrm{sp}^{2}$ ): from 5.12 to $6.39 \mathrm{ppm}$ for $\mathrm{H} 2$, and from 37.05 to $93.71 \mathrm{ppm}$ for C2. In addition, reactIR monitoring shows the appearance of bands at 1375 and $1610 \mathrm{~cm}^{-1}$ upon formation of 6 . These data are diagnostic for $\kappa^{1}$ coordination of the trifluoroacetate group to the Pd center (see ESI, fig S2). ${ }^{11}$ Attempts to isolate and crystallize 6 failed so far, thus the exact nature of the fourth ligand at $\mathrm{Pd}\left(\mathrm{X}=\mathrm{Cl}\right.$ or $\left.\mathrm{CF}_{3} \mathrm{CO}_{2}\right)$ remains unknown.

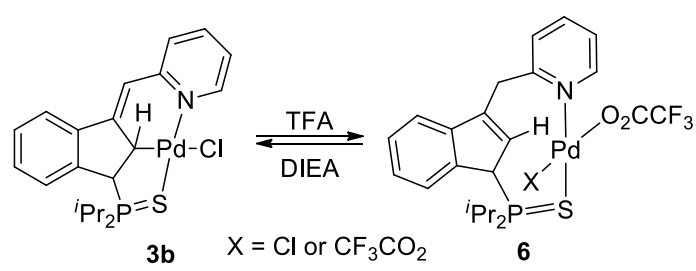

Scheme 5. Equilibrium between $\mathbf{3 b}$ and $\mathbf{6}$ under Brönsted acid-base conditions

Interestingly, the transformation of $\mathbf{3 b}$ into $\mathbf{6}$ is reversible. Following the formation of $\mathbf{6}$ by reacting 3b with 3 equivalents of TFA, 3 equivalents of a base (DIEA) were added. NMR showed instantaneous and quantitative reformation of $\mathbf{3 b}$ (Figure 4). Thus, the cleavage / formation of the C2-Pd bond is reversible under Brönsted acid/base conditions. The protonation of the C2-metalated ligand likely represents the initial stage of ligand dissociation under strongly acidic conditions. Conversely, the formation of the C2-Pd bond from $\mathbf{6}$ is reminiscent of the formation of the SCS bis(thiophosphinoyl) methylindenyl Pd pincer complex. ${ }^{12}$

Despite the low stability of $\mathbf{4}$ in solution, we were curious about the impact that the pyridine sidearm may have on catalytic activity. Therefore, the activity of $\mathbf{4}$ was evaluated in the cycloisomerization of 4-pentynoic acid as a model reaction for which complete conversion was observed after $1 \mathrm{~h}$ with the palladium indenediide dimer $\left[\operatorname{Ind}\left({ }^{i} \mathrm{Pr}_{2} \mathrm{P}=\mathrm{S}\right)_{2} \mathrm{Pd}\right]_{2} .{ }^{4 \mathrm{~b}, 13}$ The reaction was carried out in $\mathrm{CDCl}_{3}$ at room temperature, with $5 \mathrm{~mol} \%$ of catalyst loading and in the absence of any external base (Scheme 6). The reaction proceeded readily and $62 \%$ conversion into the 5 -exo lactone was observed after $1 \mathrm{~h}^{14}$ In order to elucidate the potential role of the methylpyridine sidearm, we performed a few control experiments. First, complex 7 was prepared by adding 2 equivalents of triphenylphosphine to the 
corresponding indenediide dimer and engaged in the catalytic cycloisomerization reaction. In this case, the catalytic activity was completely shut down (no reaction after $1 \mathrm{~h}$ at room temperature), most likely due to the saturation of the Pd coordination sphere by $\mathrm{PPh}_{3}$. This control experiment is consistent with the need of a free coordination site for the $\pi$ activation of the $\mathrm{C} \equiv \mathrm{C}$ triple bond and thus suggests that the labile character of the methylpyridine is involved in the catalytic transformation. Given this, both the indenediide moiety and the pyridine moiety may contribute to the deprotonation (and activation) of the carboxyl acid group. A second control experiment was thus performed using the protonated chloroindenyl complex $\mathbf{3} \mathbf{b}$. In this case, no conversion was detected after $1 \mathrm{~h}$, indicating that decoordination of pyridine is not enough for the cycloisomerization to occur, confirming thereby the necessity of the electron-rich indenediide moiety in addition to the free coordination site at $\mathrm{Pd}$.

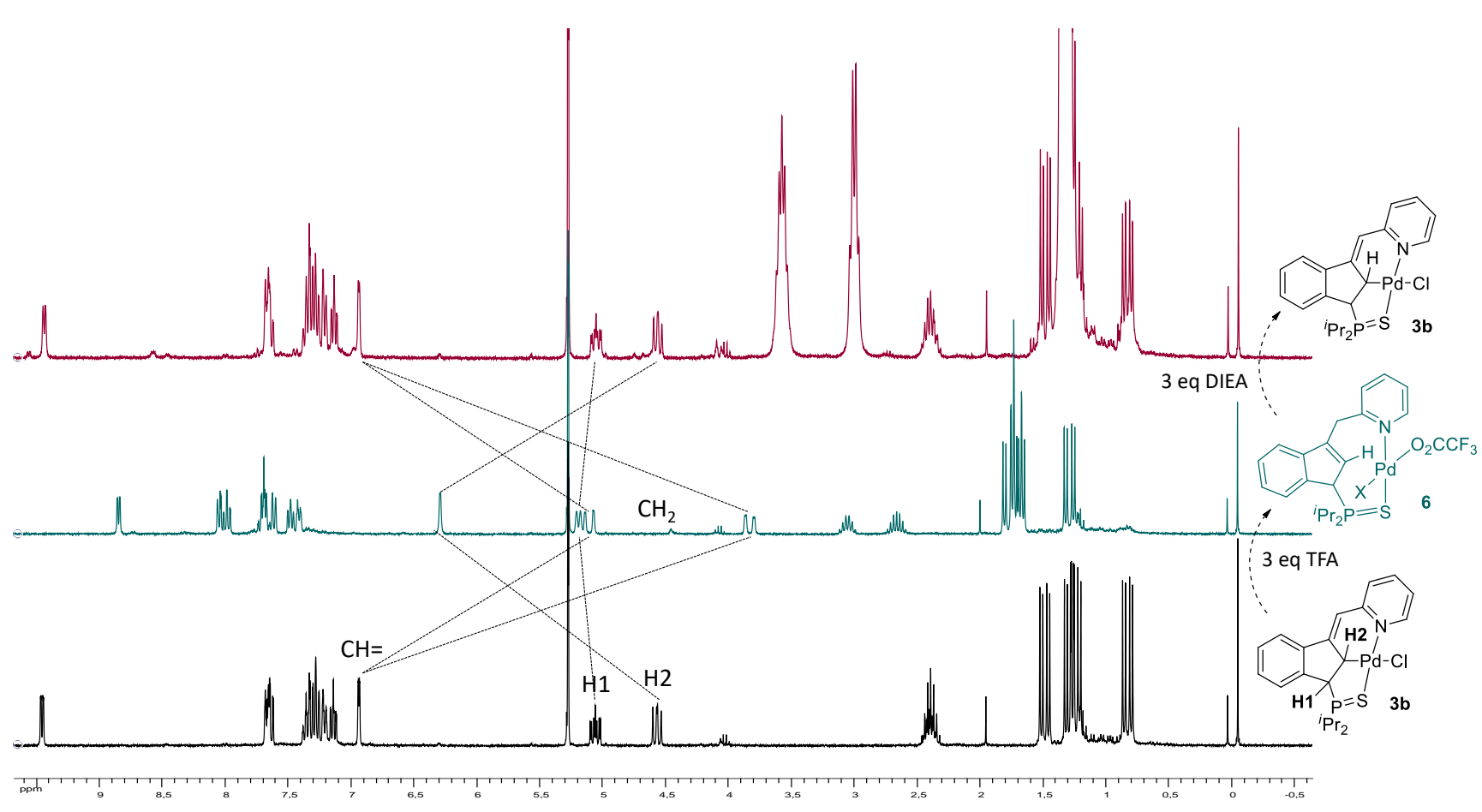

Figure 4. ${ }^{1} \mathrm{H}$ NMR monitoring of the addition of trifluoroacetic acid (3 equivalents, turquoise spectrum) and then $\mathrm{N}, \mathrm{N}$-diisopropylethylamine (3 equivalents, red spectrum).

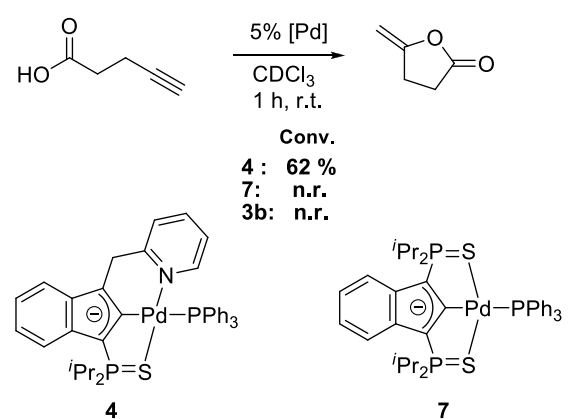

Scheme 6. Evaluation of the catalytic performances of indenediide Pd complexes $\mathbf{4}, \mathbf{7}$ and $\mathbf{3 b}$ in the cyclization of 4-pentynoic acid. (Conversions estimated by ${ }^{1} \mathrm{H}$ NMR spectroscopy)

\section{Conclusions}

In summary, the new unsymmetrical indene based pro-ligand $\mathbf{2}$ featuring thiophosphinoyle and methylpyridine sidearms was prepared. Coordination to Pd afforded three isomeric complexes 3a-c that 
were separated and fully characterized. Competition experiments in the presence of Lewis bases demonstrate the lability of the methylpyridine sidearm of $\mathbf{3}$ while Brönsted acid/base conditions promotes reversible cleavage of the C2-Pd bond. A new SCN indenediide complex 4 stabilized by a triphenylphosphine co-ligand was also prepared. Preliminary catalytic tests underlined the impact of the methylpyridine sidearm on catalytic activity.

These results illustrate the interest and potential that hemilability may have on catalytic applications of indenediide pincer complexes. We have previously demonstrated that subtle structural modulations of the thiophosphinoyle sidearms can enhance greatly the robustness of indenediide Pd complexes. ${ }^{4 \mathrm{~b}}$ Future work will aim to increase the stability of such unsymmetrical indenediide complexes by modification of the thiophosphinoyle sidearm, with the aim to take advantage of the hemilabile character of the pyridine moiety in catalysis.

\section{Acknowledgements}

Financial support from the Centre National de la Recherche Scientifique, the Université de Toulouse and the Agence Nationale de la Recherche (ANR CE6-CYCLOOP) is acknowledged. We thank Corinne Routaboul (ICT, Toulouse) for helpful assistance with the in situ infrared experiment with the ReactIR.

\section{Notes and references}

1 J. R. Khusnutdinova and D. Milstein, Angew. Chem. Int. Ed., 2015, 54, 12236.

2 For selected examples, see: (a) C. Gunanathan and D. Milstein, Acc. Chem. Res., 2011, 44, 588; (b) C. Gunanathan and D. Milstein, Chem. Rev., 2014, 114, 12024; (c) T. Zweifel, J. V. Naubron, T. Büttner, T. Ott and H. Grützmacher, Angew. Chem. Int. Ed., 2008, 47, 3245; (d) T. Zweifel, J. V. Naubron and H. Grützmacher, Angew. Chem. Int. Ed., 2009, 48, 559; (e) D. Gelman and S. Musa, ACS Catal., 2012, 2, 2456; (f) S. Musa, L. Ackermann and D. Gelman, Adv. Synth. Catal., 2013, 355, 3077; (g) A. V. Polukeev and O. F. Wendt, J. Organomet. Chem., 2018, 867, 33.

3 For selected examples, see: (a) T. Zell and D. Milstein, Acc. Chem. Res., 2015, 48, 1979; (b) N. Gorgas and K. Kirchner, Acc. Chem. Res., 2018, 51, 1558; (c) F. Kallmeier and R. Kempe, Angew. Chem. Int. Ed., 2018, 57, 46; (d) A. Kumar, T. Janes, N. A. Espinosa-Jalapa and D. Milstein, Angew. Chem. Int. Ed., 2018, 57, 12076; (e) Y. K. Jang, T. Krückel, M. Rueping and O. El-Sepelgy, Org. Lett., 2018, 20, 7779; ( $f$ ) C. Erken, A. Kaithal, S. Sen, T. Weyhermüller, M. Hölscher, C. Werlé and W. Leitner, Nat. Commun., 2018, 9, 4521; $(g)$ D. Oren, Y. Diskin-Posner, L. Avram, M. Feller and D. Milstein, Organometallics, 2018, 37, 2217; (h) T. Irrgang and R. Kempe, Chem. Rev., 2019, doi:10.1021/acs.chemrev.8b00306.

4 (a) A. Scharf, I. Goldberg and A. Vigalok, J. Am. Chem. Soc., 2013, 135, 967; (b) N. Á. Espinosa-Jalapa, D. Ke, N. Nebra, L. Le Goanvic, S. Mallet-Ladeira, J. Monot, B. Martin-Vaca and D. Bourissou, ACS Catal., 2014, 4, 3605; (c) P. Brunel, J. Monot, C. E. Kefalidis, L. Maron, B. Martin-Vaca and D. Bourissou, ACS Catal., 2017, 7, 2652.

5 (a) L. C. Gregor, C. H. Chen, C. M. Fafard, L. Fan, C. Guo, B. M. Foxman, D. G. Gusev and O. V. Ozerov, Dalton Trans., 2010, 39, 3195; (b) C. C. Comanescu and V. M. Iluc, Organometallics, 2014, 33, 6059; (c) C. C. Comanescu and V. M. lluc, Organometallics, 2015, 34, 4684; (d) C. C. Comanescu and V. M. lluc, Polyhedron, 2018, 143, 176.

6 (a) R. G. Pearson, J. Am. Chem. Soc., 1963, 85, 3533; (b) R. G. Pearson, J. Chem. Educ., 1968, 45, 581; (c) R. G. Pearson, J. Chem. Educ., 1968, 45, 643.

7 (a) A. Fleckhaus, A. H. Mousa, N. S. Lawal, N. K. Kazemifar and O. F. Wendt, Organometallics, 2015, 34, 1627; (b) A. H. Mousa, A. Fleckhaus, M. Kondrashov and O. F. Wendt, J. Organomet. Chem., 2017, 845, 157.

8 V. Vresch, J. Monot, B. Martin-Vaca and D. Bourissou, Polyhedron, 2018, 143, 49.

9 Attempts to increase the stability of this indenediide complex by the introduction of other co-ligands were unsuccessful.

10 M. Gagliardo, N. Selander, N. C. Mehendale, G. Van Koten, R. J. Klein Gebbink and K. Szabó, Chem. Eur. J., 2008, 14, 4800.

11 K. Nakamoto, Infrared and Raman Spectra of Inorganic and Coordination Compounds: Part B: Applications in Coordination, Organometallic, and Bioinorganic Chemistry, Sixth Edition, Wiley-VCH, Weinheim 2014.

12 N. Nebra, J. Liséna, N. Saffon, L. Maron, B. Martin-Vaca and D. Bourissou, Dalton Trans., 2011, 40, 8912.

13 J. Monot, P. Brunel, C. E. Kefalidis, N. A. Espinosa-Jalapa, L. Maron, B. Martin-Vaca and D. Bourissou, Chem. Sci., 2016, 7, 2179.

14 No further conversion was observed after $1 \mathrm{~h}$. 